\title{
The Validity Of Gibrat's Law: Evidence From Manufacturing Industry In Iran: 1995-98
}

\author{
Mohammad Ali Feizpour, University of Yazd, Iran \\ Vahid Mahmoudi, University of Tehran, Iran, and University of California Riverside, USA \\ Ebrahim Soltani, University of Kent Business School, UK
}

\begin{abstract}
Using transition matrices, in this paper we have shown that Gibrat's Law is rejected for manufacturing plants in Iran over the period 1995-98. We find that size is an important variable in the study of plant growth for manufacturing industries in Iran.
\end{abstract}

Keywords: Gibrat's Law, Transition matrices, Iran

\section{INTRODUCTION}

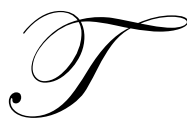

he re-emergence of small-scale plants and the negative relationship between size and growth of firms has characterized the manufacturing industries of most developed countries since the early 1970s (Taymaz, 2001). There are a number of reasons for this; including greater innovation and entrepreneurship, greater flexibility afforded by smaller scale, and government policy, which has encouraged enterprise (see Keeble, 1997, and Harris and Robinson, 2001).

In most European countries, for example, the relative number of small-sized enterprises in manufacturing industries (those with less than 100 employees) is growing and employment is concentrated in this size class (Trau, 1997 and Hart, 1999). Furthermore, in the field of industrial economics, the size-growth relationship has been of great interest to academics, and it is often applied to the analysis of the firm-size distribution and market structure, either at the industry level or for the overall economy.

The relationship between plant size and growth is important. If, for example, the growth rate of firms in a fixed population of firms is independent of the initial size, then the concentration of the population increases without limit (Caves, 1998), so that as time passes a few firms will obtain most of market share (in terms of output or employment). In this vein, Gibrat (1931) argues that the growth of a firm is independent of its initial size (known as Gibrat's Law) and consequently, that the firm-size distribution is log-normal. However, most recent studies based on longitudinal data show that the firm growth is not independent of the initial firm size. The recent studies show that smaller firms grow at faster rates in comparison with their larger counterparts, and as a consequence the size distribution of firm sizes is right skewed. Due to the availability of data, Segarra and Callejon (2000) note that most of the research on the relationship between size and growth, i.e. on the validity of Gibrat's Law, has only been possible within the last decade. Indeed, according to my knowledge, no work has been done concerning the relationship between firm size and growth in Iran up until time.

The purpose of this paper is to examine the role of firm size on the growth of manufacturing plants in Iran during the Second Development Plan (1995-99). In Iran, unemployment is a serious problem, and if it is shown that the size of a firm has a significant effect on its growth (eg. the growth rate of a small enterprise is higher than for its larger counterpart) then from a policy point of view as a way of reducing unemployment this should act as an incentive for programmes that promote the birth, survival and growth of small firms. 
This paper is organized as follows. The data is described in section 2. Section 3 is an empirical test of Gibrat's Law utilizing data on manufacturing industries in Iran, employing transition matrices method. Section 4 concludes.

\section{THE DATA}

The Statistical Centre of Iran resumed the annual implementation of the Survey of Manufacturing Establishments in 1992. This covered all manufacturing plants with at least 10 employees. However, to provide much more detail on the nature of plants, the General Census of Manufacturing and Mines (GCMM) was implemented in 1995. This covers all manufacturing and mining plants with at least 10 employees, but a sample of establishments with less than 10 employees were surveyed for the years 1995 through to 1998. In total, the GCMM surveys about 13,000 to 14,000 plants annually. This includes 11,500 plants that have 10 or more employees, and a sample of around 2,000 smaller plants.

In terms of plant-level analysis of Gibrat's Law, we just include those plants with less than 500 employees for which we have plant-level data in order to maximize the number of observations. Further, we just consider those plants that were surveyed in 1995 and follow their growth through to 1998. Although using a short cross section of data to test the validity of Gibrat's Law may be problematic (Geroski et al., 2003) however, they are the only data at our disposal.

Table 1 shows that there are a total of 12,712 plants in 1995 (with less than 500 employees), and of these 10,109 survived to 1998 (79.5 percent). Further, of these 12,712 plants, 10,750 were initially in the employment size group 10 to 500, of which 8,177 were still in this size group at 1998. However, another 361 (the decliners) had shrunk to less than 10 employees by this time, so that 79.4 percent survived. Of the 1,962 plants that had less than 10 employees at 1995, 1,571 were still in this size group at 1998, i.e. 80.1 percent (see Feizpour, 2003 for more details).

Table 1: Plant Level Data, 1995-98

\begin{tabular}{lcccc}
\hline \multicolumn{1}{c}{ Size Classes } & $\mathbf{1 9 9 5}$ & $\mathbf{1 9 9 6}$ & $\mathbf{1 9 9 7}$ & $\mathbf{1 9 9 8}$ \\
\hline $\mathbf{e m p}<\mathbf{1 0}$ & 1,962 & 1,857 & 1,891 & 1,932 \\
$\mathbf{e m p}<\mathbf{1 0}(1995$ sampled)) & $(1,962)$ & $(1,838)$ & $(1,582)$ & $(1,571)$ \\
$\mathbf{e m p}<\mathbf{1 0}$ (decliners)) & $(0)$ & $(19)$ & $(309)$ & $(361)$ \\
$\mathbf{1 0} \leq \mathbf{e m p}<\mathbf{5 0 0}$ & 10,750 & 10,394 & 8,561 & 8,177 \\
\hline Total Plants & 12,712 & 12,251 & 10,452 & 10,109 \\
\hline Total Employment & 464,382 & 469,130 & 400,239 & 378,396 \\
\hline
\end{tabular}

Data source: Statistical Centre of Iran (SCI), 2002

\section{THE VALIDITY OF GIBRAT'S LAW IN IRAN USING TRANSITION MATRICES}

There are at least three different ways to test the validity of Gibrat's Law of Proportionate Effect to examine the role of firm size on firm growth; these are: transition matrices, parametric tests and non-parametric methods. In this section we utilize transition matrices method to test the validity of Gibrat's Law in Iran. It should be pointed out that our examination of Gibrat's Law is conducted at the individuals manufacturing plant level, where the operation takes place at a single, physical location.

Transition matrices are one way to compare different size distributions of firms at the beginning and end of a period. When new plant entries are controlled for, the idea behind this approach is that the transfer of a firm from one size class to another size class is the result of firm growth. If Gibrat's Law holds, the rate of transfers between different size classes should be roughly constant (for example, the percentage of firms that transfer from a small-size class to a medium-size class should be approximately equal to the percentage of firms that transfer from a mediumsize class to a large-size class). To test for Gibrat's Law in this way requires that size classes are constructed, and of course there are a number of ways to do this. We divide the firms into size classes in three different ways in order to 
provide a fairly rigorous assessment of this approach. Firstly, the firms are divided into five groups: 1-9 employees, 10-49, 50-99, 100-249 and 250 employees or more. Secondly, since most of the firms fall within the smallest size classes (1-9 and 10-49 employees), we further sub-divide these two classes to give a total of nine size classes. Finally, the size classes are arranged so that they contain a similar number of plants (again, the number of classes is set equal to nine). Table 2, 3 and 4 show the respective results of the transition matrices for each of these three different classifications.

Table 2: Transition Matrix, 1995-1998

\begin{tabular}{cccccc}
\hline Size Class & $\mathbf{1}$ & $\mathbf{2}$ & $\mathbf{3}$ & $\mathbf{4}$ & $\mathbf{5}$ \\
\hline 1 & 59.13 & 40.61 & 0.19 & 0.06 & 0.00 \\
2 & 14.10 & 80.11 & 5.17 & 0.60 & 0.03 \\
3 & 1.18 & 27.62 & 54.97 & 15.71 & 0.52 \\
4 & 0.20 & 3.61 & 13.25 & 72.29 & 10.64 \\
5 & 0.00 & 0.43 & 0.86 & 14.22 & 84.48 \\
\hline
\end{tabular}

$(1=1$ thru 9$)(2=10$ thru 49$)(3=50$ thru99 $)(4=100$ thru 249$)(5=250$ thru 499$)$

Table 3: Transition Matrix, 1995-1998 (The Number of Plants in Each Class is not Equal)

\begin{tabular}{|c|c|c|c|c|c|c|c|c|c|}
\hline Size Class & 1 & 2 & 3 & 4 & 5 & 6 & 7 & 8 & 9 \\
\hline 1 & 41.21 & 33.23 & 23.96 & 0.32 & 0.64 & 0.32 & 0.00 & 0.32 & 0.00 \\
\hline 2 & 12.24 & 43.08 & 42.13 & 1.35 & 0.64 & 0.32 & 0.24 & 0.00 & 0.00 \\
\hline 3 & 5.45 & 15.85 & 65.80 & 7.88 & 2.88 & 1.19 & 0.86 & 0.07 & 0.02 \\
\hline 4 & 1.22 & 3.33 & 32.63 & 35.13 & 16.35 & 6.28 & 4.42 & 0.64 & 0.00 \\
\hline 5 & 0.62 & 1.99 & 16.00 & 18.49 & 26.92 & 19.98 & 14.27 & 1.74 & 0.00 \\
\hline 6 & 0.42 & 0.84 & 7.14 & 11.13 & 16.39 & 30.46 & 30.25 & 3.15 & 0.21 \\
\hline 7 & 0.52 & 0.65 & 3.14 & 5.24 & 6.02 & 13.22 & 54.97 & 15.71 & 0.52 \\
\hline 8 & $0.00-$ & 0.20 & 1.61 & 0.40 & 0.80 & 0.80 & 13.25 & 72.29 & 10.64 \\
\hline 9 & 0.00 & 0.00 & 0.00 & 0.00 & 0.43 & 0.00 & 0.86 & 14.22 & 84.48 \\
\hline
\end{tabular}

$(1=1$ thru 5) $(2=6$ thru 9$)(3=10$ thru 14) $(4=15$ thru 19) $(5=20$ thru 25$)(6=26$ thru 49$)(7=50$ thru 99) $(8=100$ thru 249) $(9=250$ thru 499)

Table 4: Transition Matrix, 1995-1998 (The Number of Plants in Each Class is Equal)

\begin{tabular}{cccccccccc}
\hline Size Class & $\mathbf{1}$ & $\mathbf{2}$ & $\mathbf{3}$ & $\mathbf{4}$ & $\mathbf{5}$ & $\mathbf{6}$ & $\mathbf{7}$ & $\mathbf{8}$ & $\mathbf{9}$ \\
\hline 1 & 55.11 & 18.28 & 12.27 & 8.67 & 3.86 & 0.52 & 0.52 & 0.69 & 0.09 \\
2 & 28.88 & 25.72 & 19.68 & 14.80 & 7.85 & 1.81 & 0.63 & 0.63 & 0.00 \\
3 & 22.03 & 18.39 & 20.73 & 22.64 & 11.80 & 1.82 & 1.56 & 0.95 & 0.09 \\
4 & 12.19 & 9.80 & 15.24 & 25.78 & 23.23 & 6.43 & 4.28 & 2.39 & 0.66 \\
5 & 7.50 & 6.44 & 8.38 & 19.59 & 31.07 & 11.30 & 9.53 & 5.74 & 0.44 \\
6 & 3.50 & 3.05 & 3.86 & 9.87 & 21.45 & 23.34 & 21.18 & 12.21 & 1.53 \\
7 & 2.50 & 2.20 & 2.50 & 5.51 & 10.01 & 14.91 & 30.93 & 26.83 & 4.60 \\
8 & 0.89 & 0.71 & 0.71 & 2.41 & 3.84 & 6.08 & 12.78 & 52.64 & 19.93 \\
9 & 0.45 & 0.18 & 0.36 & 0.45 & 0.72 & 0.72 & 2.08 & 7.88 & 87.14 \\
\hline
\end{tabular}

$(1=1$ thru 8$)(2=9$ thru 10) $(3=11$ thru 12) $(4=13$ thru 15) $(5=16$ thru 19) $(6=20$ thru 25) $(7=26$ thru35) $(8=36$ thru 64) $(9=65$ thru 499)

The rows of Tables 2, 3 and 4 refer to the size class at 1995, while the columns give the size class at 1998 . Therefore, entries above the leading diagonal show the proportion (i.e. percentage) of firms in each size class at 1995 that have transferred to a larger size class at 1998. The converse applies to entries below the leading diagonal (hence each of the rows sums to 100 percent).

The transition matrices reveal several interesting findings. The first is the relatively large number of enterprises that do not change size class (i.e. they lie along the leading diagonal of the matrices). Secondly, the results of the transition matrices only to some extent depend on the particular size classification, but the broad picture is the same across each table. Finally, for most size classes (except size class 2 in Tables 2 and 3 ) there are fewer growing firms than shrinking firms, since most of the entries lie above the leading diagonal. For example, in 
Table 4 the average value of a transition above the leading diagonal is 6.68 percent, whereas below the diagonal it is only 5.70 percent. To sum up, the transition matrices do not provide strong support for Gibrat's Law. Transfers towards larger size classes (above the leading diagonal) are much more numerous than transfers towards lower size classes. This implies that smaller plants grow at faster rates. Consequently, the relationship between size and growth seems not to be constant, as predicted by Gibrat.

\section{4}

\section{CONCLUSIONS}

According to Gibrat's Law, which is also known as the Law of Proportionate Effect, firm growth is independent of initial firm size. Using transition matrices method in this paper we have shown that Gibrat's Law is rejected for manufacturing plants in Iran over the period 1995-98. Thus, we find that size is an important variable in the study of plant growth for manufacturing industries. The implication of this is that plant size should be an important consideration in the policymaker's attempts to create employment in Iran as a remedy for unemployment.

\section{AUTHOR INFORMATION}

Dr. Mohammad Ali Feizpour is currently Associate Professor at the Department of Economics, University of Yazd, Iran. He received his Ph.D. in Industrial Economics from University of NewCastle, UK and has been full time faculty over 15 years. He has published over 30 papers mainly on industrial and small and medium enterprises. During 2004-2008, he served as the Chair of the Department of Economics at the University of Yazd.

Dr. Vahid Mahmoudi is Associate Professor at the Department of Finance, University of Tehran, and currently Visiting Professor at the Department of Economics, University of California Riverside. Mahmoudi received his Ph.D. in Development Economics from University of Essex, UK in 2001. He has published over 40 papers mainly on development economics issues. He has published a scholarly book titled measuring poverty and income distribution in Iran and also translated three books of Amartya Sen to Persian.

Dr. Ebrahim Soltani is currently senior lecturer in operational management at the Department of Management Science, University of Kent Business School, Canterbury, UK. He received his Ph.D. in quality management from University of Strathclyde, UK. He has published over 20 papers in top journals, mainly in the journal of Total Quality Management. He also has some book contributions.

\section{REFERENCES}

1. Caves, R. E. Industrial organization and new findings on the turnover and mobility of firms. Journal of Economic Literature 36(4). 1998.

2. Feizpour, M. A. Manufacturing industrial change and the role of small and medium-sized enterprises in Iran. Department of Economics. Newcastle, University of Newcastle upon Tyne. 2003.

3. Geroski, P. A etal. Are differences in firm size transitory or permanent?" Journal of Applied Econometrics 18: 47-59. 2003.

4. $\quad$ Gibrat, R. Les inegalites economiques. Paris, Sirey. 1931.

5. Harris, R. and C. Robinson. DTI Industrial support policies. Research Project, (SEC01), Department of Trade and Industry, London. 2001.

6. Hart, M. Small firms, economic growth and public policy: what exactly are the connections? Scott Policy Seminar Series, Belfast, NIERC. 1999.

7. Keeble, D. Small firms, innovation and regional development in Britain in the 1990s. Regional Studies 31(3): 281-293. 1997.

8. Segarra, A. and M. Callejon. New firm's survival and market turbulence: new evidence from Spain. Review of Industrial Organization 20: 1-14. 2002.

9. Taymaz, E. Small and medium enterprises in Turkish manufacturing industries." Journal of Economic Cooperation 22(1): 43-72. 2001.

10. $\quad$ Trau, F. Recent trends in the size structure of Italian manufacturing firms." Small Business Economics 9: 273-285. 1997. 